ORIGINAL ARTICLE

\title{
A Study on Maternal Weight Gain and its Correlation with Birth Weight of Baby at Term
}

\author{
*S Rijvi ${ }^{1}, *$ S Abbasi ${ }^{2}$, A Karmakar $^{3}$, SF Siddiqui ${ }^{4}$, F Dewan $^{5}$
}

\begin{abstract}
Background: Maternal weight gain is influenced by several trends in perinatal health that are of great public health concern. Maternal weight gain during the 2 nd and 3rd trimesters is an important determinant of fetal growth

Objective: To determine the relationship between maternal weight gain and birth weight of baby at term.

Methodology : A cross sectional observational study was carried among 50 pregnant women at term were admitted in the Department of Obstetrics and Gynaecology, Shaheed Suhrawardy Medical College and Hospital and Anwer Khan Modern Medical College hospital during the period of January 2014 to July 2014. Data were collected pre-designed data collection sheet.

Results: This study found maximum (36\%) were age group $21-25$ years followed by $28 \%$ were $\leqslant 20$ years, $24 \%$ were $26-30$ years, $8 \%$ were $31-35$ years and only $4 \%$ were $36-40$ years. The average age was 25 years. Among these 50 pregnant women, 2 cases (4\%) had BMI <18.5, 15 cases (30\%) had a BMI 18.5$24.9,19$ cases $(38 \%)$ had a BMI $25-29.9$ and 14 cases $(28 \%)$ had a BMI $\geqslant 30$. The mean birth weight was $2.77 \pm 0.33$. kg. Mean weight gain was $10.72 \pm 3.72 \mathrm{Kg}$. Weight increased there was a corresponding increase in the mean birth weight and this relationship was statistically significant $(<0.05)$.

Conclusion: This study shows maternal weight gain significantly increased birth weight of the baby at term. Maternal weight should continue to be given importance in monitoring the health of pregnancies and bioelectrical impedance analysis and arm measurements should be further investigated as another simple way to track appropriate body composition changes across gestation, especially in resource-limited settings. Although challenging, public health efforts should continue working to improve the nutritional status of women of reproductive age before they conceive as an apparent way to improve birth outcomes.
\end{abstract}

Key Words: Maternal weight gain, Birth weight

\section{Introduction}

Birth weight is an important predictor for survival and health. ${ }^{1}$ Infants with a low birth weight (less than 2,500 $\mathrm{g}$ or more than $4000 \mathrm{~g}$ ) have increased perinatal morbidity and mortality as well as an increased risk of adulthood hypertension and type 2 diabetes. ${ }^{2}$ For many years the focus has been on increasing birth weight, which is positively

correlated with maternal weight gain during pregnancy. However, although a high maternal weight gain tend to decrease the incidence of low birth weight, an excessive weight gain may entail fetal as well as maternal complications, such as pregnancy and delivery complications and obesity later in life. ${ }^{3}$

1Dr. Shiffin Rijvi, Registrar, Dept of Obstetrics and Gynecology, Anwer Khan Modern Medical College Hospital

${ }^{2}$ Dr. Sharmin Abbasi, Assistant Professor, Dept of Obstetrics and Gynecology, Anwer Khan Modern Medical College Hospital

${ }^{3}$ Dr. Anuradha Karmakar, Registrar, Dept of Obstetrics and Gynecology, Delta Medical College Hospital

4 Professor Sehereen Farhad Siddiqua, Head Dept of Obstetrics and Gynecology, Anwer Khan Modern Medical College Hospital

5Professor Farhana Dewan, Head Dept of Obstetrics and Gynecology, Ibna Sina Medical College and Hospital

*Corresponding author

Date of submission: 21.08.2017, Date of acceptance: 05.10.2017 
Prepregnancy body mass index (BMI) is an important predictor of birth weight. It is therefore important to combine maternal weight gain and prepregnancy BMI in analyses of the association between weight gain and infant birth weight. In the American Institute of Medicine (IOM) introduced weight gain recommendations for pregnant women with different recommendations for underweight (BMI less than $19.8 \mathrm{~kg} / \mathrm{m}^{2}$ ), normal weight (19.8 $\left.26.0 \mathrm{~kg} / \mathrm{m}^{2}\right)$, overweight $\left(26.1-29.0 \mathrm{~kg} / \mathrm{m}^{2}\right)$, and obese women (BMI more than $29.0 \mathrm{~kg} / \mathrm{m}^{2}$ ). ${ }^{2}$ Weight gain during pregnancy has been associated with high birth weight and measures of adiposity early in life. Because high birth weight predicts BMI later in life, these findings suggest that excessive weight gain during pregnancy could raise the long-term risk of obesity-related disease in offspring. High birth weight might also increase risk of other diseases later in life, including asthma, atopy, and cancer. ${ }^{3}$

Low weight gain in pregnancy is associated with increased risk of preterm delivery, particularly if women are underweight or of average weight before pregnancy. But still there is increasing evidence that higher weight gains during pregnancy do not improve infant outcomes and instead may elevate the mothers' long-term risk of chronic disease. 4 Sally et al. found that mean birth weight of infant increased by $20.2 \mathrm{~g}$ per kilogram of weight gain during pregnancy. ${ }^{5}$ In study conducted by Abrams and Selvin too, the mean birth weight of the infant increased by $22.6 \mathrm{~g} / \mathrm{kg}$ GWG. ${ }^{6}$ In the study by Nahar was $5.69(\mathrm{SD}=1.95) \mathrm{kg} .{ }^{7}$

Birth weight was correlated both with maternal weight in early pregnancy and with weight gain during pregnancy, but only $10 \%$ of the variation in birth weight was explained by these maternal factors. Mean maternal weight $24 \mathrm{~h}$ postpartum was equal to the weight at 14 weeks of pregnancy, implying, on the average, no net weight gain. Women with a positive net weight gain had heavier babies than women with a negative net weight gain. Maternal anthropometric characteristics are important underlying determinants of intrauterine growth and birth weight, but they explain only a minor part of the variation and are of little value for screening purposes in individual women. ${ }^{8}$
Maternal weight gain is one of the most important independent predictors of infant birth weight. Birth weight (BW) is an important determinant of infant's well being. Several factors such as mothers' genetic characteristics, socio-cultural, demographic, behavioural factors, prepregnancy body mass index (BMI), gestational weight gain (GWG) etc contribute to birth weight. BW is important as low birth weight is known to increase the risk of adult onset diseases like type- 2 diabetes and ischemic heart disease. ${ }^{12}$

Nevertheless, maternal weight gain is associated with large infants i.e., macrosomia $(>4000 \mathrm{~g}$ ) or large for gestational age infants who have higher risk of birth injuries and other problems like shoulder dystocia, fractures of the clavicles or limbs, and perinatal asphyxia. The total amount of weight gained in normal-term pregnancies varies considerably among women and the variance appears to be due to many maternal characteristics and pregnancy outcomes. ${ }^{13}$

Weight gain during pregnancy has always been a matter of great concern for most women and obstetricians. This concern exists because gestational weight gain is related to many complications, both maternal and fetal.Macrosomia is a major fetal complication, consisting of cases of infants born weighing more than 4,000 g, regardless of the gestational age. ${ }^{9}$ This large weight is associated with complications for both the mother and the child. The most common complications in macrosomic fetuses include: increased risk of intrauterine death, hypertrophic cardiomyopathy, need for intensive care, shoulder dystocia, humeral and clavicle fractures, meconium aspiration, hypoglycemia, neonatal hyperbilirubinemia, paralysis of the facial and brachial plexus and obesity in childhood and adulthood. ${ }^{10}$ For mothers, the most common complications include: increased risk of cesarean section, cephalopelvic disproportion, prolonged labor, soft-tissue lacerations and postpartum hemorrhage. ${ }^{11}$

The present study was designed to determine the maternal weight gain and birth weight of baby at term. This study also help the planner of the hospital especially for resource allocation for weight gain of mother and birth weight babies at term. 


\section{Objective}

To determine the relationship between maternal weight gain and birth weight of new born at term.

\section{Materials and Methods}

It was cross sectional observational study in department of Obstetrics and Gynaecology, Shaheed Suhrawardy Medical College and Hospital and Anwer Khan Modern Medical college hospital from January 2014 to July 2014.

50 Pregnant women were included in study. Inclusion criteria were all pregnant women at term who were in regular antenatal checkup (37 completed weeks of gestational age). Exclusion criteria were: The pregnant women suffering from Hypertension, Pre-eclampsia, Eclampsia, Diabetes mellitus, Thyroid dysfunction, Nephritis. Data were collected in pre-designed data collection sheet. A structured questionnaire was developed and pre-tester before administration by the author. Data was collected from the pregnant mother admitted in the in-patient department for a period of 6 months. The data were collected face to face interview for relevant information and measured the weight and height of the women before delivery and weight of the neonate were measured following delivery. Mother's weight was measured by a valid \& reliable weighing machine. Mother's height was measured with a height measuring scale. A valid and reliable neonatal weighing machine determined the neonatal weight. Written informed consent was taken from each patient. Prior to consent they were explained the aim and purpose of the research. Confidentiality was assured and anonymity was maintained; no participants were identified in any report or publication under this study.

\section{Results}

Table-I: Age distribution of the patients $(n=50)$

\begin{tabular}{cccc}
\hline Age in years & Frequency & Percent & Mean \pm SD \\
\hline$\leq 20$ & 14 & 28.0 & \\
$21-25$ & 18 & 36.0 & \\
$26-30$ & 12 & 24.0 & \\
$31-35$ & 4 & 8.0 & $25.00 \pm 5.43$ \\
$36-40$ & 2 & 4.0 & \\
Total & 50 & 100.0 & \\
\hline
\end{tabular}

Table shows maximum (36\%) were age group 21-25 years followed by $28 \%$ were $\leqslant 20$ years, $24 \%$ were $26-30$ years, $8 \%$ were $31-35$ years and only $4 \%$ were $36-40$ years. The average age was 25 years.
Table-II: BMI of the patients $(n=50)$

\begin{tabular}{lcc}
\hline BMI & Frequency & Percent \\
\hline Under weight $\left(<18.5 \mathrm{~kg} / \mathrm{m}^{2}\right)$ & 2 & 4.0 \\
Normal $\left(18.5-24.9 \mathrm{~kg} / \mathrm{m}^{2}\right)$ & 15 & 30.0 \\
Overweight $\left(25-29.9 \mathrm{~kg} / \mathrm{m}^{2}\right)$ & 19 & 38.0 \\
Obese $\left(>30 \mathrm{~kg} / \mathrm{m}^{2}\right)$ & 14 & 28.0 \\
Total & 50 & 100 \\
\hline
\end{tabular}

Table shows $4 \%$ were underweight, 30\% were normal weight, $38 \%$ were over weight and $28 \%$ were obese.

Table-III: Weight gain during pregnancy $(\mathrm{n}=50)$

\begin{tabular}{cccc}
\hline Weight gain (Kg) & Frequency & Percent & Mean \pm SD \\
\hline$\leq 5$ & 2 & 4.0 & \\
$6-10$ & 34 & 68.0 & $10.72 \pm 3.72$ \\
$>10$ & 14 & 28.0 & \\
Total & 50 & 100.0 & \\
\hline
\end{tabular}

Among 4\% of women, weight gain during pregnancy was $\leqslant 5 \mathrm{~kg}$ in $68 \%$ weight gain was $6-10 \mathrm{~kg}$ and $28 \%$ weight gain was $>10 \mathrm{~kg}$. The mean weight gain was $10.72 \pm 3.72 \mathrm{Kg}$

Table-IV: Mode of delivery $(\mathrm{n}=50)$

\begin{tabular}{lcc}
\hline Mode of delivery & Frequency & Percent \\
\hline Normal vaginal delivery & 26 & 52.0 \\
LUCS & 24 & 48.0 \\
Total & 50 & 100.0 \\
\hline
\end{tabular}

Table shows $52 \%$ women delivered vaginally and $48 \%$ underwent LUCS

Table-V: Birth weight of new born $(n=50)$

\begin{tabular}{cccc}
\hline Birth weight & Frequency & Percent & Mean \pm SD \\
\hline$\leq 2.5 \mathrm{~kg}$ & 12 & 24.0 & \\
$>2.5 \mathrm{~kg}$ & 38 & 76.0 & $2.77 \pm 0.33$ \\
\hline
\end{tabular}

Table shows that $24 \%$ of the new born has birth weight $\leqslant 2.5 \mathrm{~kg}$ and $76 \%$ had birth weight $>2.5 \mathrm{Kg}$. The mean birth weight was $2.77 \pm 0.33$ 
Table-VI: Relationship between maternal weight gain and birth weight of new born $(n=50)$

\begin{tabular}{ccccc}
\hline $\begin{array}{c}\text { Maternal weight } \\
\text { gain (Kg) }\end{array}$ & Number & \multicolumn{2}{c}{ Birth weight } & \multirow{2}{*}{ P value } \\
\cline { 3 - 4 } & Mean & SD & \\
\hline $55 \mathrm{Kg}$ & 2 & 2.40 & 0.00 & \\
$6-10 \mathrm{Kg}$ & 34 & 2.73 & 0.33 & 0.007 \\
$>10 \mathrm{Kg}$ & 14 & 3.06 & 0.20 & \\
\hline
\end{tabular}

Table shows birth weight was $2.40 \mathrm{~kg}$ in maternal weight gain $\leqslant 5 \mathrm{~kg}$, birth weight was $2.73 \mathrm{~kg}$ in maternal weight gain 6-10 kg and birth weight 3.06 $\mathrm{kg}$ in maternal weight gain $>10 \mathrm{~kg}$. So it is indicated that with an increase in weight gain during pregnancy there was a corresponding increase in mean birth weight and this increase was statistically significant $(P<0.05)$.

Table-VII: Relationship between BMI and birth weight $(n=50)$

\begin{tabular}{lcccc}
\hline \multirow{2}{*}{ BMI } & Number & \multicolumn{2}{c}{ Birth weight } & P value \\
\cline { 3 - 4 } & & Mean & SD & \\
\hline $\begin{array}{l}\text { Under weight }(<18.5 \\
\left.\mathrm{kg} / \mathrm{m}^{2}\right)\end{array}$ & 2 & 2.20 & 0.00 & \\
$\begin{array}{l}\text { Normal }(18.5-24.9 \\
\left.\mathrm{kg} / \mathrm{m}^{2}\right)\end{array}$ & 15 & 2.56 & 0.35 & 0.001 \\
$\begin{array}{l}\text { Overweight }(25-29.9 \\
\left.\mathrm{kg} / \mathrm{m}^{2}\right)\end{array}$ & 21 & 2.84 & 0.24 & \\
Obese $\left(>30 \mathrm{~kg} / \mathrm{m}^{2}\right)$ & 12 & 3.00 & 0.19 & \\
\hline
\end{tabular}

Table shows that under weight mother had significantly lower birth weight and overweight and obese mother had significantly higher birth weight. This findings found statistically significant correlation between BMI and birth weight $(P<0.05)$.

\section{Discussion}

Maternal weight gain during pregnancy influenced by several trends in perinatal health that are of great public health concern. Women are increasingly gaining weight during pregnancy complications associated with excess gestational weight gain such as large-for-gestational-age babies. This is also important as the prevalence of Cesarean delivery has also increased. Maternal weight gain during the 2nd and $3^{\text {rd }}$ trimesters is an important determinant of fetal growth. Low maternal weight gain is associated with an increased risk of small for gestational age (SGA) infants, especially in underweight and normal-weight women. ${ }^{14}$

Birth weight is perhaps the most important and reliable indicator for neonatal and infant survival, its physical growth and mental development. As a universal indicator, it can be used to describe the health, nutrition and socio-economic status of population in both developed and developing countries. Currently, the incidence of low birth weight in India is 33 percent and as per National Health Policy efforts are being made to bring down the incidence to 10 percent by the year 2000 AD. ${ }^{15}$

This study found maximum (36\%) were age group $21-25$ years followed by $28 \%$ were $\leqslant 20$ years, $24 \%$ were $26-30$ years, $8 \%$ were $31-35$ years and only $4 \%$ were $36-40$ years. The average age was 25 years. This findings consisted with Rao et al. ${ }^{16}$ study they found 25.2 years. Majority of the study subjects were housewives (88\%), literate $(60 \%)$, and belonged to middle income group (60\%). This study found majority were house wife $(88 \%)$. Regarding educational status, $4 \%$ were illiterate, $36 \%$ were can sign only, $12 \%$ were primary education, $20 \%$ were secondary education, $20 \%$ were higher secondary and $8 \%$ were master degree. In monthly income, $4 \%$ were monthly upper income group ( $>10000 /$ month), $60 \%$ were middle income group ( $>5000-10000 /$ month) and $36 \%$ were lower income group ( $<5000 /$ month). Height of the study subject, $8 \%$ had birth weight $\leqslant 45 \mathrm{Kg}, 16 \%$ had birth weight $46-55 \mathrm{Kg}, 40 \%$ had birth weight 56-65 $\mathrm{Kg}$ and $36 \%$ had birth weight $>65 \mathrm{Kg}$. Among these 50 pregnant women, 2 cases $(4 \%)$ had BMI $<18.5$, 15 cases $(30 \%)$ had a BMI 18.5-24.9, 19 cases (38\%) had a BMI 25-29.9 and 14 cases (28\%) had a $\mathrm{BMI} \geqslant 30$. These women were categorized in BMI under weight, normal, overweight and obese. Yazdani et al. ${ }^{17}$ study shows Among these 1000 pregnant women; 128 cases $(12.8 \%)$ had BMI $<19.9,412$ cases $(41.2 \%)$ had a BMI 20-24.9, 356 cases $(35.6 \%)$ had a BMI $25-29.9,98$ cases $(9.8 \%)$ had a BMI 30-34.9 and 6 cases (0.6\%) had a $\mathrm{BMI} \geqslant 35$.

This study shows $24 \%$ of the new born has birth weight $\leqslant 2.5 \mathrm{~kg}$ and $76 \%$ had birth weight $>2.5 \mathrm{Kg}$. 
The mean birth weight was $2.77 \pm 0.33$. $\mathrm{kg}$. The observed mean birth weight in the present study is comparable to studies conducted by Prasad et al. ${ }^{18}$ and Rodrigues et al. ${ }^{19}$ who observed a mean birth weight of $2823.6 \mathrm{gm}(\mathrm{SD}=417.8 \mathrm{gm})$ and 2815.0 gm $(\mathrm{SD}=449.3 \mathrm{gm})$ respectively. In this study shows among $4 \%$ of women, weight gain during pregnancy was $\leqslant 5 \mathrm{~kg}$ in $68 \%$ weight gain was $6-10$ $\mathrm{kg}$ and $28 \%$ weight gain was $>10 \mathrm{~kg}$. The mean weight gain was $10.72 \pm 3.72 \mathrm{Kg}$. This findings consisted with Rao et al. ${ }^{20}$ study. The mean weight gain during pregnancy obtained in this study was also comparable to other studies carried out in India. ${ }^{21,22}$ However, the studies conducted by Barbara $^{23}$ and Ekblad et $a l^{24}$ found mean weight gains during pregnancy of $15.4 \mathrm{~kg}(\mathrm{SD}=5.2 \mathrm{~kg})$ and $13.0 \mathrm{~kg}(\mathrm{SD}=3.0 \mathrm{~kg})$ respectively which were higher than the findings of the present study.

In this study, we observed that there was a significant correlation between maternal weight gain and fetal birth weight. It is indicated that with an increase in maternal weight gain during pregnancy there was a corresponding increase in mean birth weight and this increase was statistically significant $(\mathrm{P}<0.05)$. This findings consisted with Moreira et $a l .{ }^{25}$ and they found significant correlation between maternal weight gain during pregnancy and birth weight of the new born. Another study Hymphreys ${ }^{26}$ reported maternal weight gain during gestation is positively correlated with birth weight. A population-based study conducted in the United States has shown that maternal weight gain during pregnancy correlates with birth weight. ${ }^{27}$ Rao et al. ${ }^{28}$ evaluated the relationship between various factors such as multiparity, pregestational overweight or obesity, advanced maternal age, prolonged gestational age and excessive gestational weight gain with the manifestation of fetal macrosomia. In that study, only excessive gestational weight gain was significantly associated with macrosomia. ${ }^{29}$ Many studies conducted in India $^{30,31}$ and in different parts of the world ${ }^{32,33}$ have proved the positive relationship between weight gain during pregnancy and birth weight. This study found significant association of BMI during pregnancy and birth weight of the new born. It found BMI below normal associated with low birth weight and BMI $>30$ higher birth weight. The latter result is similar to other studies from Ushakiran $^{44}$ and Bhattacharya. ${ }^{34}$ Yazdani et al. reported BMI below normal is associated with a low birth rate, while a BMI $>30$ increases the chance on a higher birth weight (2500-4000 or higher). This only suggests that weight gain during pregnancy is perhaps the most important variable irrespective of maternal height and period of gestation. It is a well established fact that period of gestation has an independent effect on birth weight.

\section{Conclusion}

Weight gain during pregnancy, and maternal weight have emerged as maternal factors influencing the birth weight of the baby. In the present study, it was found that there was a direct relationship between maternal weight gain and fetal birth weight. Although challenging but public health efforts should continue working to improve the nutritional status of women of reproductive age before they conceive as an apparent way to improve birth outcomes.

\section{Conflict of interest: None}

\section{References}

1. Viswanathan M, Siega-Riz AM, Moos MK, et al. Outcomes of maternal weight gain. Evid Rep Technol Assess 2008; (168): 1-223.

2. Rode L, Hegaard HK, Kjærgaard $\mathrm{H}$, et al. Association Between Maternal Weight Gain and Birth Weight. Obstetrics \& Gynecology 2007; 109(6): 1309-1315.

3. Ludwig DS, Currie J. The association between pregnancy weight gain and birthweight: a within-family comparison. The Lancet 2010; 376(9745): 984 - 990,

4. Karim MR, Flora MS, Akhter S. Targeted food supplementation through National Nutrition Program and pregnancy weight gain status in selected upazilas. Bangladesh Med Res Counc Bull 2011; 37: 71-75.

5 . Nahar S, Mascie-Taylor CGN, Begum HA. Maternal anthropometry as a predictor of birth weight. Public Health Nutr 2006; 10: 965-70. 
6. Ledermann SA, Paxton A, Heymsfield SB, et al. Maternal body fat and water during pregnancy: Do they raise infant birth weight? Amer J Obstet Gynecol 1999; 180: 235-40.

7. Barbara Adams and Steve Selvin. Maternal weight gain pattern and birth weight. Obstet Gynecol 1995; 86: 163-9.

8. Möller B, Gebre-Medhin M, Lindmark G. Maternal weight, weight gain and birth weight at term in the rural Tanzanian village of Ilula. Br J Obstet Gynaecol. 2009 Feb; 96(2): 158-66.

9. Costa BM, Paulinelli RR, Barbosa MA. Association between maternal and fetal weight gain: cohort study. Sao Paulo Med. J. 2012; 130(4): 242-247.

10. Clausen T, Burski TK, Øyen N. Maternal anthropometric and metabolic factors in the first half of pregnancy and risk of neonatal macrosomia in term pregnancies. A prospective study. Eur J Endocrinol. 2005; 153(6): 887-94.

11. Stotland NE, Cheng YW, Hopkins LM, et al. Gestational weight gain and adverse neonatal outcome among term infants. Obstet Gynecol. 2006; 108(3 Pt 1): 635-43.

12. Padilha PDC, Accioly E, Chagas C, et al. Birth weight variation according to maternal characteristics and gestational weight gain in Brazilian women. Nutr Hosp 2009; 24: 207-12.

13. Shrestha I, Sunuwar L, Bhandary S, et al. Correlation between gestational weight gain and birth weight of the infants. Nepal Med Coll J 2010; 12(2): 106-109

14. Misra VK, Hobel CJ, Sing CF. The effects of maternal weight gain patterns on term birth weight in African-American women. J Matern Fetal Neonatal Med 2010; 23(8): 842-849.

15. Lantz ME, Chez RA, Rodriguez A, et al. Maternal Weight Gain Patterns and Birth Weight Outcome in Twin Gestation. Obstet Gynaecol 1996; 87: 551-6.
16. Sirikul SJ, PAWANICH PS, Koranantakul O, et al. Influence of maternal nutrient intake and weight gain on neonatal birth weight: A prospective cohort study in southern Thailand. The Journal of Maternal-Fetal and Neonatal Medicine, November 2009; 22(11): 1045-1050.

17. Moller BO, Gebre-Medhin M, Lindmark G. Maternal weight, weight gain and birthweight at term in the rural Tanzanian village of Ilula. British Journal of Obstetrics and Gynaecology 2009; 96: 158-166.

18. Panahandeh Z. Gestational Weight Gainand Fetal Birth Weight in Rural Regions of Rasht/Iran. Iran J Pediatr 2009; 19 (No 1): 1923.

19. Shrestha I, Sunuwar L, Bhandary S, et al. Correlation between gestational weight gain and birth weight of the infants. Nepal Med Coll J 2010; 12(2): 106-109.

20. Lawoyin TO. Maternal weight and weight gain in Africans. Its relationship to birth weight. J Trop Pediatr. 1991; 37(4): 166-71.

21. Weight gain during pregnancy. Committee Opinion No. 548. American College of Obstetricians and Gynecologists. Obstet Gynecol 2013; 121: 210-2.

22. Siega-Riz AM, Viswanathan M, Moos MK, et al. A systematic review of outcomes of maternal weight gain according to the Institute of Medicine recommendations: birthweight, fetal growth, and postpartum weight retention. Am J Obstet Gynecol 2009; 201: 339. e1-14.

23. Modified from Institute of Medicine (US). Weight gain during pregnancy: reexamining the guidelines. Washington, DC. National Academies Press; National Academy of Sciences 2009

24. Langford A, Joshu C, Chang JJ, et al. Does gestational weight gain affect the risk of adverse maternal and infant outcomes in overweight women? Matern Child Health J 2011; 15: 860-5. 
25. Beyerlein A, Schiessl B, Lack N, von Kries R. Optimal gestational weight gain ranges for the avoidance of adverse birth weight outcomes: a novel approach. Am J Clin Nutr 2009; 90: 1552-8.

26. Blomberg M. Maternal and neonatal outcomes among obese women with weight gain below the new Institute of Medicine recommendations. Obstet Gynecol 2011; 117: 1065-70.

27. Potti S, Sliwinski CS, Jain NJ, et al. Obstetric outcomes in normal weight and obese women in relation to gestational weight gain: comparison between Institute of Medicine guidelines and Cedergren criteria. Am J Perinatol 2010; 27: 415-20.

28. Malik S, Radha G, Udani R, et al. Maternal biosocial factors affecting low birth weight, Indian Journal of Pediatrics, 1997; 64: 373-7.

29. Metcoff J. Fetal malnutrition and SGA are not synonymous. Clinical assessment of nutritional status at birth. Pediatrics Clinics of North America, 2004; 41(5) : 875-87.
30. Singh M. Care of the Newborn, Fifth edition, New Delhi: Sagar Publications, 1999: 2, 40, $58,68,224-41$.

31. Rao PRS, Prakash KP, Nair S. Influence of PrePregnancy Weight, Maternal Height and Weight Gain During Pregnancy on Birth Weight. Bahrain Medical bulletin 2001; 23(1): 75-85.

32. Yazdani S, Yosofniyapasha Y, Nasab BH, et al. Effect of maternal body mass index on pregnancy outcome and newborn weight. BMC Research Notes 2012; 5: 34.

33. Lemeshow S, Hosmer DW Jr, Klar J. Adequecy of sample size in health studies: Statistical methods for sample size determination. World Health Organization, Geneva, p. 35.

34. Prasad KN, Phaneendra Rao RS. Study of low birth weight infants in coastal areas of Udupi Taluk, Karnataka, South India. Bahrain Med Bull 1994; 16: 90-4. 